
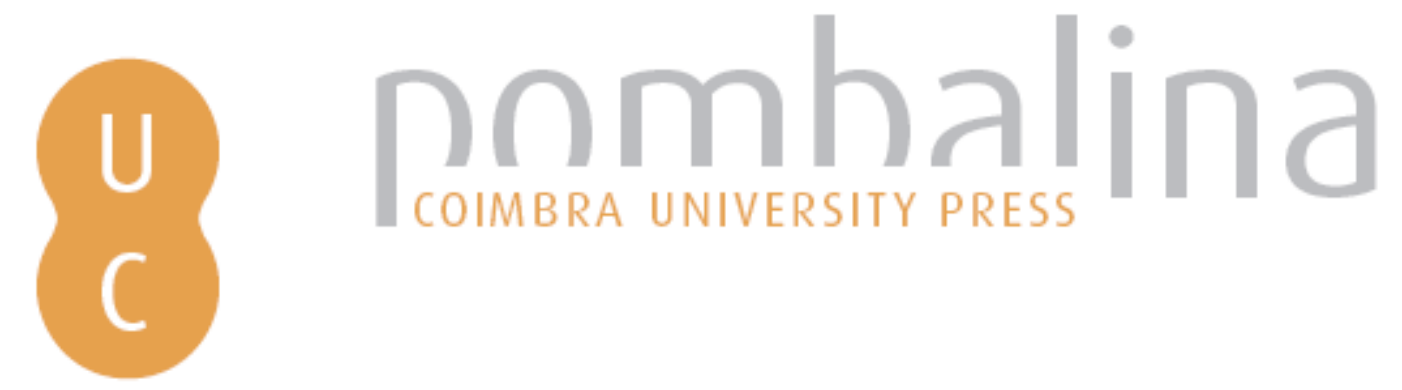

\title{
Identidade e diferença, expressões superficiais: sobre o “Uso da Intuição” como fundamento da compreensão em Simmel
}

\author{
Autor(es): $\quad$ Franco, Reynner \\ Publicado por: Imprensa da Universidade de Coimbra \\ URL \\ persistente: URI:http://hdl.handle.net/10316.2/38240 \\ DOI: $\quad$ DOI:http://dx.doi.org/10.14195/978-989-26-1049-8_6 \\ Accessed : $\quad$ 26-Apr-2023 10:53:17
}

A navegação consulta e descarregamento dos títulos inseridos nas Bibliotecas Digitais UC Digitalis, UC Pombalina e UC Impactum, pressupõem a aceitação plena e sem reservas dos Termos e Condições de Uso destas Bibliotecas Digitais, disponíveis em https://digitalis.uc.pt/pt-pt/termos.

Conforme exposto nos referidos Termos e Condições de Uso, o descarregamento de títulos de acesso restrito requer uma licença válida de autorização devendo o utilizador aceder ao(s) documento(s) a partir de um endereço de IP da instituição detentora da supramencionada licença.

Ao utilizador é apenas permitido o descarregamento para uso pessoal, pelo que o emprego do(s) título(s) descarregado(s) para outro fim, designadamente comercial, carece de autorização do respetivo autor ou editor da obra.

Na medida em que todas as obras da UC Digitalis se encontram protegidas pelo Código do Direito de Autor e Direitos Conexos e demais legislação aplicável, toda a cópia, parcial ou total, deste documento, nos casos em que é legalmente admitida, deverá conter ou fazer-se acompanhar por este aviso.

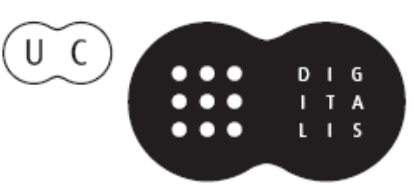



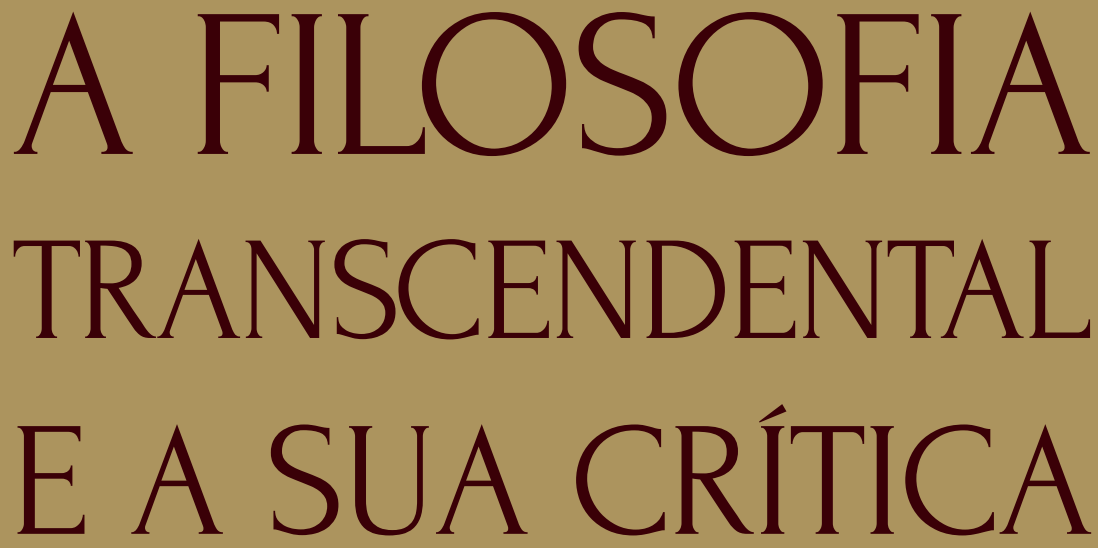

IDEALISMO • FenOMENOLOGIA • HERMENÊUTICA

\author{
DIOGO FERRER \\ LUCIANO UTTEICH \\ (COORDENADORES)
}


IDENTIDADE E DIFERENÇA, EXPRESSÕES SUPERFICIAIS: SOBRE O “USO DA INTUIÇÃO” COMO FUNDAMENTO DA COMPREENSÃO EM SIMMEL

IDENTITY AND DIFERENCE, SUPERFICIAL EXPRESSIONS: ABOUT THE "USE OF INTUITION" AS THE BASIS OF COMPREHENSION IN SIMMEL

Reynner Franco*

(Universidad de Salamanca)

Abstract: The controversy surrounding the historical comprehension and the suprahistorical comprehension provides Simmel with some keys to criticize the mechanistic conception of intuition, grounded on the assumption that comprehension is reached by processes of interaction of identical and/or different elements. Against this, Simmel redefines the meaning (and the elements) of the interaction of comprehension itself by suggesting the notion of "use of intuition" as a connecting thread to come to understand. This approach is related to Simmel's particular - pragmatic-evolutionary-vitalist - turn on Kant's transcendentalism. The "use of intuition" is revealed as a factual way to access a

*rfranco@usal.es

Reynner Franco é Professor na Universidade de Salamanca, e tem por domínio principal de investigação as áreas da Metafísica, Epistemologia, Intuicionismo, Intersubjectividade e Idealismo Alemão. 
supraindividual "vital totality". In terms of both, its function and its content, this notion could form the main support or foundation of comprehension, which should be taken as a field or condition of the deduction.

Keywords: Historical comprension; suprahistorical comprehension; intuition; vitalist pragmatism; transcendentalism; Simmel

Resumo: A controvérsia em torno da compreensão histórica e supra-histórica oferece a Simmel algumas chaves para criticar a concepção mecanicista da intuição, atravessada pelo suposto de que a compreensão se consuma mediante processos de interacção entre elementos idênticos e/ou diferentes. Contra esta posição, Simmel redesenha o sentido (e os elementos) da interacção própria da compreensão, propondo a noção de "uso da intuição" como fio condutor do compreender. Este enfoque articula-se com a sua viragem especifica, pragmático-evolutivo-vitalista, do transcendentalismo kantiano. $\mathrm{O}$ "uso da intuição" revela-se como o modo fáctico de aceder a uma "totalidade vital" supra-individual. Tanto pela sua função, como pelo seu conteúdo, esta noção poderia corresponder ao principal suporte ou fundamento da compreensão, a qual deve ser suposta com o âmbito ou a condição da dedução.

Palavras-Chave: Compreensão histórica; compreensão supra-histórica; intuição; pragmatismo vitalista; transcendentalismo; Simmel

Um dos principais - e mais discretos - contributos para a relação entre a filosofia transcendental, a hermenêutica e o intuicionismo encontra-se na ontologia vitalista de Georg Simmel. Tal como o entendo, o seu conceito de "compreensão" (fusão da compreensão histórica e supra-histórica) antecipa, de certo modo, a viragem 
ontológica da compreensão exposta por Heidegger em Ser e Tempo. A possível diferença entre ambas as concepções - que refiro somente a título de introdução - poderia consistir em que Heidegger concebe a compreensão como um existenciário, a saber, o do "poder ser", como o que se projecta sobre as suas possibilidades, reservando a "interpretação" (ou exposição, Auslegung) para o desenvolvimento de cada uma das possibilidades ${ }^{370}$ - como a relação que pode haver entre situar-se perante um tabuleiro de xadrez antes de começar a jogar e mover a primeira peça, - ao passo que para Simmel a compreensão é um "protofenómeno" - num sentido parecido com o de "existenciário" heideggeriano, - estreitamente vinculado ao "ritmo" do vital. Uma espécie de registo dinâmico, "supra-individual", segundo Simmel, cujas conformidades e objectivações (exteriorizações) transcendem o ponto de vista da vivência própria, pois partem de um "fluir unitário" em que os acontecimentos se encontram relacionados e que cada um de nós verifica - em parte de modo adequado, e em parte de modo inadequado - como "realizações do seu espírito" no decurso da história.

Assim, se cada um procurasse fazer uma sinopse da história das realizações do espírito humano, poderia experimentar, segundo propõe Simmel, o seu próprio espírito como vivendo em tais realizações e, ao mesmo tempo (como veremos mais abaixo), que tais realizações são - de modo "objectivo" - supraindividuais, sem que as possamos decompor ou separar mais além. O que experimentamos tem mais que ver, segundo Simmel, com a actualização e crescimento da nossa própria "força intuitiva". Simmel ilustra-o do seguinte modo:

"na medida em que, considerando a arte italiana, chego à rigidez bizantina e à falta de movimento de diversos modos do Trecento, ao relaxamento individualizante do Quattrocento e, depois à unidade harmoniosamente compreendida do

370 Cf. Heidegger (1967), § 32. 
último Renascimento, experimento o meu espírito enquanto vive nestas suas realizações e, dilatando-se passo a passo, actualiza progressivamente a sua força intuitiva." 371

Precisamente, a controvésia entre a compreensão histórica e a supra-histórica oferece a Simmel as chaves para criticar o ponto de vista mecanicista, que tenta dar razão da compreensão supondo como cindidos elementos superficiais (e até mesmo erróneos). A compreensão histórica (que é a percepção da actualização ou desdobramento da nossa "força intuitiva") consiste fundamentalmente em reconhecer o desenvolvimento - pressupondo um "sujeito ideal" capaz de fazer um tal caminho - da compreensão de momentos não deduzíveis entre si, cujo carácter atemporal nos situa por si próprio no "que" da compreensão, naquilo que temos de compreender: "nunca compreenderíamos o quê das coisas a partir do seu desenvolvimento histórico, se não compreendêssemos de algum modo esse mesmo quê; pelo contrário, evidentemente, todo o empreendimento seria de todo sem sentido." 372 Por outras palavras, a compreensão supra-histórica pode condicionar a histórica e, se isto é assim, os elementos que configuram o possível dualismo subjacente aos problemas centrais da compreensão não teriam que ver com a separação clássica entre as dimensões "internas" e "externas", mas antes entre o que Simmel descreve como "conteúdo anímico e conteúdo atemporal". 373 Ambos os conteúdos se dão de modo interactivo, e Simmel considera-os elementos que contêm o carácter de interdependência que, em grande medida, dá forma ao domínio da compreensão: “[aqueles elementos] mostram já na sua própria permanência ideal relações e dependências mútuas;

371 Simmel (1999), 176. Versão castelhana: Simmel (2001), 179. (Incluo a paginação da tradução castelhana a seguir à da edição alemã, separadas por "/". Os excertos são traduzidos a partir da tradução castelhana, que alterei ligeiramente nalguns casos).

372 Simmel (1999) 171/172.

373 Cf. Simmel (1999) 171/172. 
são, por assim dizer, símbolos atemporais da sua realização anímica temporal, as duas coisas em interdependência recíproca profundamente fundamentada." ${ }^{374}$ Embora esta tese mereça uma análise específica, para as finalidades deste trabalho será suficiente - inicialmente - situar nela as razões por que se gera uma possível (e problemática) distinção entre os dois tipos de compreender (histórico e supra-histórico), em cuja contraposição Simmel encontra modos muito estreitos de interpenetração incondicionada (ou relativamente condicionadas). Como exemplo desta relação complexa poderíamos citar o seguinte passo de Simmel: "ao lado da afirmação de que a compreensão de Kant está condicionada pela sua dedução histórica, pode colocar-se esta outra: que a sua dedução histórica está condicionada pela sua compreensão." 375

Mas esta interacção não é possível, segundo Simmel, por meio de algum processo de "assimilação" ou "transmissão" - cuja indemonstrabilidade e superficialidade o autor destaca reiteradamente, - processos que recaem necessariamente numa concepção atomista ou realista, que requer a pressuposição de uma identidade essencial, ou aspira alcançar um conhecimento das coisas "tal como são realmente". ${ }^{376}$ Mas tão-pouco parte esta interacção de uma diferença absoluta, embora Simmel reconheça que esta interacção procura fundar uma relação com uma alteridade incomparável, na medida em que se trata de um protofenómeno: o tu, categoria que Simmel considera "tão decisiva para a construção do mundo prático e histórico, como a de substância ou de causalidade para o mundo científico-natural," 377 e que é equivalente à compreensão, ou antes, são o mesmo, como define Simmel: "o tu e o compreender são precisamento o mesmo, por assim dizer, expresso uma vez como substância e outra como função; são um pro-

\footnotetext{
374 Simmel (1999) 171/172.

375 Simmel (1999) $173 / 174$.

376 Cf. Simmel (1999) 159/155.

377 Simmel (1999) 161/157.
} 
tofenómeno do espírito humano, como o ver e o ouvir, o pensar e o sentir, ou como a objectividade em geral como espaço e tempo, como o eu." ${ }^{378}$ De um ponto de vista básico, tanto a compreensão histórica como a "objectiva" - trans-histórica, supra-histórica ou atemporal consistiriam na função de interacção própria da relação do eu (espírito ou sujeito) com a alteridade (como segunda pessoa), entendida esta como um fenómeno originário com o qual se estabelece uma relação de trato ("entre tu e tu"), um modo recíproco de actuar um sobre o outro baseado na "via de uso" - por assim dizer - de intuições a que temos acesso e que desenvolvemos graça ao nosso carácter vital.

Isto situa-nos no ponto de vista organicista (vitalista) que se contrapõe à concepção mecanicista da intuição, encerrada nos intrincados pressupostos de que a compreensão se alcança por meio de processos de intercâmbio, transmissão (ou associação) de elementos idênticos e/ ou dissemelhantes.

\section{O uso da intuição}

Aquilo que dá forma ao ponto de apoio de Simmel encontra-se no que poderíamos descrever - de modo provisório - como o "correlato" (ou "denotador") dos acontecimentos, ou seja, aquilo pela qual somos capazes de assinalar, ou mesmo descrever, um acontecimento, sem necessidade de o circunscrever a sujeitos a quem algo acontece, à sucessão temporal da qual podem surgir ou, em suma, às condições que o tornam possível. ${ }^{379}$ Simmel descreve-o, mais concretamente, como a "utilização da intuição" que, para o compreender histórico, "está envolvida pelo seu uso, absolutamente inevitável, a cada instante da

378 Simmel (1999) 162/158.

379 Num sentido que me parece similar ao que descreve Waldenfelds a propósito dos "acontecimentos sem atributos" de Robert Musil, cf. Waldenfels (2004). 
vida prática." 380 Este "uso da intuição" perfila-se, em Simmel, como aquilo que compreendemos realmente da histórica, intrinsecamente vinculado "ao que acontece", tendo em atenção que a referida compreensão está condicionada pela interacção que levanta a pergunta: "como acontece que um homem compreenda outro homem?"381

Se é correcta a tese de que o possível fundamento transcendental desta interacção se encontra no mencionado "uso da intuição", e que deste modo evitamos um longo caminho de pontes que medeiem entre os supostos - que tão-pouco sabemos com certeza se se encontram separados - então o que temos de esclarecer é a origem, desenvolvimento e comunicabilidade desta intuição. Supõe-se que para Simmel esta via evita muitos problemas típicos dos preconceitos clássicos que deixam por esclarecer os processos de interacção. Uma teoria que dê razão da compreensão por meio da empatia (e.g. Schleiermacher ou Dilthey), ou por meio da associação das próprias vivência com as expressões externas é insuficiente, especialmente dadas as dificuldaades e pressuposições do estabelecimento de relações entre experiências de dois tipos (interno-externa e externo-interna): “a experiência própria interno-externa não oferece a chave da experiência alheia externo-interna", de facto, esta chave só se requer "por causa da lamentável cisão do homem em corpo e alma." 382 Esta via representa um desvio (ou dilatação) considerável, além de que a possível interacção sob estes termos ficaria reduzida basicamente a processos de projecção cuja função seria equivalente à descrição de uma "mudança" espiritual, "assim como quem leva os seus móveis para uma casa que está vazia" 383 - como comenta Simmel ironicamente - com a particularidade de que no caso da compreensão o transporte é demasiado especulativo.

\footnotetext{
380 Simmel (1999) 163/160.

381 Simmel (1999) 154/146.

382 Simmel (1999) 157/151.

383 Simmel (1999) 160/156.
} 
No contexto da compreensão histórica, a via intuicionista/vitalista é aberta por Simmel quando expõe a sua convicção de que percebemos "todo o homem". Se reconhecêssemos aqui uma espécie de circularidade ou dialéctica da compreensão cujos elementos contrapostos fossem tipos gerais de experiência, e cuja relação nos fosse inteiramente desconhecida, poderíamos então advertir que Simmel busca um acesso à compreensão (histórica e objectiva) por meio da totalidade da vida em desenvolvimento, razão por que as suas realizações não nos são acessíveis precisamente - conforme observámos - pela identidade ou diferença entre tais experiências, pois tanto se constatamos em outros (ou em nós mesmos) semelhanças, como se constatamos em outros vivências e desejos completamente alheios aos próprios (e precisamente por isso os compreendemos), nos dois casos seguiríamos "vias de acesso mais longas", que conduziriam talvez à compreensão, mas que o fariam de um modo sem dúvida fragmentário. A intuição opera como percepção de uma "vida global", de uma "existência total", que inicialmente pode ser compreendida de um modo pragmático, ou seja, como uma percepção baseada no modo "como o homem actua sobre o homem". ${ }^{384}$ Trata-se, por conseguinte, de um processo de "simbolização" - embora em constante desenvovimento - no sentido em que nos relacionamos com uma "totalidade" perante a qual executamos todas as nossas acções: tanto se pretendemos conservá-la como fenómeno originário, quanto se desejamos anulá-la, amá-la ou odiá-la. Em qualquer caso, a possibilidade de qualquer acção que se empreenda perante uma totalidade parte de uma percepção inicial que Simmel descreve em grande medida como um conhecimento

384 Simmel (1999) 158/152. Neste ponto Simmel parece coincidir com a concepção geral de Bergson, que situa a faculdade de compreender como um anexo da faculdade de agir, que torna possível uma adaptação cada vez mais precisa: "Na faculdade de compreender mostra-nos um anexo da faculdade de operar, uma adaptação cada vez mais complexa e mais flexível da consciência dos seres vivos em relação às condições das existências que lhe são dadas" (Bergson (1985) 9). 
primário e decisivo do outro. Um dos passos mais significativos a este respeito é o seguinte:

"percebemos antes o homem inteiro e a corporalidade isolada numa abstracção adicional a partir deste, do mesmo modo como o olho, naquilo que percebe, não vê de modo anatomicamente isolado, mas vê o homem inteiro, cuja vida global (Gesamtleben) só está presente como se estivesse canalizada através do órgão sensorial particular. Esta percepção da existência total pode ser obscura e fragmentária, susceptível de melhoria por reflexão e experiência pessoal [...], pode ser todas estas coisas, mas é o tipo unitário subjacente ao modo como o homem actua sobre o homem, é a impressão global não legitimamente analisável a partir de um ponto de vista intelectual, este é, na maioria dos casos, o primeiro e decisivo conhecimento do outro, embora susceptível de muito maior aperfeiçoamento." ${ }^{385}$

Certamente este "primeiro e decisivo conhecimento do outro" como "impressão global" da "existência total" oferece importantes dificuldades para ser analisado, embora, conforme referi, o ponto de vista pragmático pode dar sentido a uma tal percepção ("da existência total") se a conceber como modo fundamental de interacção, justificado principalmente pela incapacidade de realizar uma autêntica abstracção do todo e das partes, tal como sucede na nossa capacidade receptiva, a qual recebe as suas impressões de um modo "não-separado". Poderíamos situar aqui uma espécie de ponto (ou momento) de interacção (ou abertura) em que o percipiente e a alteridade coincidem, momento em que tem lugar a expressão e a recepção de uma "integridade" (vida global, ou existência total) canalizada - como diz Simmel - através de

385 Simmel (1999) 158/152. 
um órgão sensorial particular. Em ambos os casos (o "eu" e o "tu") trata-se de um modo de actuar de um sobre o outro, os dois executam a interacção alternando actividade e receptividade, resultando desnecessário - se não mesmo impossível - separar os elementos desta experiência "inteira", conforme resume Simmel: "todo o particular que o homem oferece é pars pro toto." 386 Se bem compreendo, o que dá sentido a esta percepção da "existência total" do outro é uma espécie de prática (ou uso) das intuições, uma acção que não permite separar o agente em partes, e só poderíamos dizer que o sujeito íntegro que age "canaliza" a sua totalidade através de algum dos seus órgãos, e do mesmo modo o recebe o percipiente. Se isto é correcto, poderíamos dizer - a partir de Simmel - que uma possível separação (analítica ou intelectual) da referida totalidade seria, mais que uma abstracção, só por si uma fragmentação, e justamente na simples captação deste carácter fragmentário da totalidade se encontra já presente a função da compreensão como protofenómeno.

\section{A intuição vital como "argumento transcendental" da compreensão (o ponto de partida do conhecimento intuitivo)}

Se queremos justificar, à maneira da argumentação transcendental em sentido kantiano, esta concepção simmeliana da compreensão como protofenómeno de interacção entre "totalidades" não poderemos deixar de considerar que a sua proposta de superação do dualismo substancial cartesiano e do dualismo epistemológico kantiano - especialmente deste último - parte de uma relação fundamental que Simmel encontra entre a teoria da selecção natural e a teoria do conhecimento, mais concretamente, a partir da sua interpretação da fundamentação do conhecimento conforme alcançada por Kant.

386 Simmel (1999) 158/152. 
Num dos seus trabalhos menos conhecidos (Über eine Beziehung der Selektionslehre zur Erkenntnistheorie), Simmel esboça aquilo que entende como um "aprofundamento" do ponto de partida fornecido pela unidade transcendental da apercepção kantiana. Como é bem conhecido, esta unidade representa o fundamento que dá razão das condições de possibilidade do conhecimento, conforme exposto nas passagens clássicas da Crítica da Razão Pura, que cabe citar aqui brevemente: “a mesma função que confere unidade às representações distintas num juízo, confere também unidade à mera síntese de representações distintas numa intuição. Unidade que, expressada de modo geral, significa o conceito puro do entendimento." ${ }^{387}$ Mais adiante, refere Kant: “a unidade transcendental da apercepção é a que reúne num conceito do objecto todo o diverso dado numa intuição. Por isso se chama unidade objectiva." 388

Embora as implicações deste modo de compreender a unidade transcendental da objectividade seja, para Simmel, crucial para a sua própria concepção do conhecimento, a principal crítica que lhe dirige é que o enfoque kantiano procura superar o dualismo ser/representação concebendo fundamentalmente o ser como uma representação:

“Se Kant superou o dualismo entre o representar e o ser concebendo também o ser como uma representação, então a unificação aqui levada a cabo [i.e., na proposta de Simmel] alcança um nível mais profundo: o dualismo entre o mundo como representação, tal como existe para nós de modo lógico-teorético, e o mundo como aquela realidade que corresponde à nossa acção prática, estaria superado pelo facto de que também as formas do pensar, que produzem o mundo como representação, são determinadas pela acção e reacção

387 Kant (1995) B 104-5.

388 Kant (1995) B 139. 
práticas que formam a nossa constituição espiritual segundo necessidades evolutivas, do mesmo modo como formam a nossa constituição corporal. E se, atendendo à sua própria expressão, a doutrina de Kant pode resumir-se na afirmação de que a possibilidade do conhecer produz igualmente para nós os objectos do conhecer, então a teoria que aqui se propõe pode significa que a utilidade do conhecer produz igualmente para nós os objectos do conhecer."389

O avanço proposto por Simmel conduz o problema a um ponto em que o mencionado dualismo epistemológico deve ou ficar superado - ao reconhecer-se que a interacção parte de necessidades evolutivas que nos afectam de um modo integral (sem distinção entre as dimensões física e mental) - ou então passar a um segundo plano, dado o constrangimento (as necessidades) que suscita ou estimula o uso da intuição, um uso no qual, como vimos acima, não parece necessária - e ainda menos "útil" - nenhuma forma de dualismo, ideia com que Simmel abre o referido ensaio: "foi já há muito expressa a conjectura de que o conhecimento humano provém das necessidades práticas da preservação e cuidado da vida." 390

Para Simmel, este pressuposto é comum ao realismo ("para o qual o conhecer é um receber e reflectir uma realidade absoluta") e o idealismo ("o qual faz determinar o conhecimento por meio de formas a priori do pensar"). A pista é dada pela viragem pragmática com que Simmel faz coincidir as expectativas de verdade de ambas as tendências sem necessidade de a formular em termos de correspondência, os quais ficariam reduzidos a meras reproduções de mecanismos de causa e efeito. O princípio da utilidade configuraria, por conseguinte, uma alternativa epistemologicamente mais plausível, porquanto oferece,

\footnotetext{
389 Simmel (1992) 74.

390 Simmel (1992) 62.
} 
segundo Simmel, uma resposta clara ao dualismo implícito tanto no referido princípio quanto na expectativa da correspondência, 391 conforme é sugerido na seguinte comparação: "posto que só o pensamento verdadeiro pode ser fundamento da actuação favorável à vida, a verdade do representar deve ser cultivada aproximadamente tanto quanto a força muscular." 392 Como se disse, a resposta de Simmel persegue um princípio unificador, não posterior, mas prévio à dualidade contida na tese citada, ou seja - conforme descreve o autor - uma "raiz comum mais profunda" entre as necessidades práticas vitais e o mundo objectivamente cognoscível. Contudo, um tal princípio não conta senão com um modo de prova a posteriori:

"Quando se diz que as nossas representações têm de ser verdadeiras, de modo a que a acção contruída sobre elas seja útil, não temos porém nenhuma outra prova senão justamente a exigência real que experimentamos por meio da actuação construída sobre elas. [...] Poderia também dizer-se porventura que não há nenhuma "verdade" teoricamente válida em razão da qual actuemos de modo conforme ao fim, mas chamamos verdadeiras àquelas representações que se evidenciaram como motivos de acção conforme ao fim e favorável à vida." 393

O princípio da necessidade baseado na aç̧ão favorável permite a Simmel reformular o representacionismo, destacando que o conteúdo das nossas representações não tem que implicar - nem é possível esclarecê-la - uma relação de semelhança entre representação e coisa representada. Pelo contrário, os conteúdos das representações pos-

391 A não ser que se coloque a questão a partir de um ponto de vista semântico ou artificial, como acontece posteriomente nas semânticas de Frege e Tarski.

392 Simmel (1992) 63.

393 Simmel (1992) 63. 
suem estruturas e funções correspondentes ao fenómeno vital e, pela a sua utilidade, - contrariamente à possibilidade kantiana - geram os objectos do conhecimento. ${ }^{394}$ Deste ponto de vista, o que opera é uma força representadora, o que conecta o elemento da causa com o do efeito é uma potência que persegue tanto a satisfação da vontade quanto um resultado externo favorável:

"Que a vontade alcance o seu fim, que satisfaça os impulsos e necessidades do sujeito, não depende, por isso, de que a representação de que parte seja congruente com a realidade a que se dirige mas, pelo contrário, ela tem de desenvolver uma força que, através das mais diversas transformações do mundo espiritual, corporal e inorgânica, culmine num resultado subjectivamente satisfatório e objectivamente favorável.

Ora, um dos principais problemas que levanta esta concepção pragmático-vitalista poderia bem ser o seguinte: é viável um conceito de verdade quando as suas concepções são chamadas verdadeiras unicamente porque foram determinadas pela selecção natural como bases para acções favoráveis? Simmel considera que sim, mas não resiste a argumentar a favor de uma verdade independente, em vista da previsão de acções bem sucedidas no futuro. A este respeito considera que tal perspectiva se deve ao preconceito de que "as causas devem ter uma semelhança morfológica com o efeito." 395 Não se requer congruência entre o conteúdo de uma representação e a realidade para levar a cabo uma volição. Pelo contrário, a vontade gera, como citámos acima, uma força que conduz o

394 Cf. Simmel (1992) 74. Noutro lugar propus uma vinculação deste aspecto do programa de Simmel com a concepção do conhecimento de Nietzsche, especialmente no que se refere ao carácter de "condição para a vida", enquanto parte da "força dos conhecimentos", cf. Franco (2008) 11ss.

395 Como nota Coleman (2002) 61. 
processo de alteração mental, física e inorgânica com vista a resultados favoráveis. Neste sentido, a distinção entre "conteúdo das representações" e "poder dinâmico representativo" é precisamente o que conduz a delimitar a noção de aquisição de conteúdos com objectividade, ou pensamento ideal, por um lado, e efeitos úteis ou favoráveis, por outro. ${ }^{396}$

Outro problema que se levanta a este respeito é o do critério para chamar verdadeiras ou falsas às representações particulares, dado que se trata de representações estabelecidas por selecção natural, na medida em que ficou provado o seu carácter favorável à vida. A resposta de Simmel é que existe uma relação imanente entre o corpo de representações que determina a verdade ou falsidade das representações particulares. Uma espécie de "coerência" entre representações que operam ao modo de axiomas que governam o sistema de representações e que, entre si mesmas são suficientes para justificar a verdade ou falsidade, embora, em última instância, se devam a um sistema cuja utilidade ficou evidenciada.

Isto permite distinguir, para Simmel, dois modos de expor o verdadeiro de uma representação sem necessidade de pressupor - à la Kant - um paralelismo metafísco entre representação e realidade absoluta. Um modo seria distinguí-los a partir da relação entre os elementos do conhecimento, cuja verdade tem lugar suposta a admissão de certos factos e princípios primeiros; ${ }^{397}$ o outro modo é considerando a totalidade do conhecimento (ou o acto de conhecer). Nas palavras de Simmel:

“Que estes mesmos axiomas sejam 'verdadeiros' em sentido teórico não é, evidentemente, outra vez teoricamente cognoscível, já que os fundamentos últimos de um domínio não podem

396 V. Coleman (2002) 62

397 Cf. Simmel (1992) 68. 
decerto ser novamente fundados dentro mas, em geral, fora do mesmo domínio. Os axiomas da geometria não são demonstráveis por via geométrica, nem os conceitos básicos do direito por via jurídica, etc. [...] Pode-se, por conseguinte, dizer que a verdade matemática existe somente entre os princípios singulares da ciência, mas a ciência, como totalidade, enquanto é suportada pelos seus axiomas, não é verdadeira no mesmo sentido em que o são os seus elementos."398

Do mesmo modo, a atenção à potência do representar como estimativa da acção favorável propõe uma resposta ao fenomenalismo elementar que resulta de uma concepção de harmonia pré-estabelecida, uma vez que, confome se mencionou antes, o ponto de partida da acção do sujeito não se encontra precisamente no conteúdo das suas representações, mas na própria potência (ou na força) de representar. ${ }^{399}$

Embora estas não sejam as únicas implicações epistemológicas das considerações de Simmel, creio que podemos acentuá-las como as mais significativas para uma aproximação ao seu modo particular do transcendentalismo kantiano. Nele encontro, naturalmente, aspectos que requerem uma análise pormenorizada, não só por ser a sua epistemologia evolutiva tão sugestiva no contexto da relação entre biologia e conhecimento, que começava a adquirir relevância no seu tempo, ${ }^{400}$ mas também pelas suas implicações e influências

398 Cf. Simmel (1992) 67-68.

399 Cf. Simmel (1992) 70.

400 Especialmente a sua afinidade às teses de Boltzmann, H. Poincaré y W. Whewell, e as suas matizes das teorias evolucionistas de Darwin, Huxley e Spencer, entre outros. A este respeto v. Campbell (1974) 455, n.77). Neste trabalho, Campbell apresenta uma interessante leitura em que destaca por exemplo, o desenvolvimento spenceriano de um "kantianismo evolucionista" (pré-darwiniano): "survival of the fittest", "rang of correspondences" (a classe hierárquica que se torna um estádio mais amplo e superior como manifestação em profundidade da distância receptiva e classe hierárquica de utilidade meio-ambiental. Este questionamento desemboca, segundo Campbell, num 
na epistemologia evolutiva contemporânea, em especial na discussão contemporânea sobre a possível incompatibilidade entre as noções de "verdade objectiva" e "selecção natural". ${ }^{401}$ No entanto, prosseguir essa análise no contexto deste trabalho excederia o âmbito hermenêutico em que se enquadra, cujo objecto principal foi situar as possíveis bases transcendentais do conceito simmeliano de compreensão, o que espero ter conseguido ao menos aproximadamente.

Na minha opinião, se há algo que pode ser descrito de um ponto de vista "transcendental" no pensamento de Simmel é a vida (na sua concepção organicista). Concretamente, conforme o que se disse antes, a "totalidade vital" como movimento, como "ritmo" - usando a sua própria expressão - é o que torna possível a compreensão, já que esta não é mais do que a "exteriorização" da referida totalidade. ${ }^{402}$ Como conclusão, retomemos a crítica reiterada de Simmel de que a compreensão não é possível (ou não se consuma) precisamente por empatia ou assimilação, mas os indivíduos viventes se

realismo ingénuo, ao aceitar o dado de facto dos processos cognitivos como fundamentalmente válidos (cf. Campbell (1974) 437). Bergson manifestar-se-ia contra esta "perfeição" spenceriana, ao passo que Simmel aceitaria uma epistemologia baseada na selecção natural. Antecipando-se a Bergson, Simmel observa que os mundos fenoménicos animais diferem uns dos outros segundo os aspectos particulares do mundo a que se adaptaram (cf. Campbell (1974) 438).

401 A partir da década de setenta começou a dar-se maior atenção às teses de Simmel, principalmente por parte de Campbell (1974), Campbell (1988) e - de modo indirecto - por Popper (1974), retomada em seguida por Coleman (2002). Poderia considerar-se que se trata de um 'primeiro relatório 'teórico não só do conteúdo do ensaio Über eine Beziehung der Selektionslehre zur Erkenntnistheorie, mas também, e principalmente, das suas implicações para a própria epistemologia evolutiva de Popper, Campbell e Coleman. Campbell incorpora Simmel ao reconhecer que apesar da sua própria intenção (e também de Popper) de refutar o pragmatismo, o instrumentalismo ou o utilitarismo subjectivo, a epistemologia baseada na selecção natural (defendida por ambos, Campbell e Popper) parece conduzi-los inelutavelmente ao pragmatismo ou ao utilitarismo. Campbell defende que Simmel expôs o problema de modo honesto, mas também forçado (tal como o fizeram Mach e Poincaré), pelo que seria necessário deter-se numa argumentação que tornasse compatível esse possível resultado (pragmático e utilitarista subjectivo) com a busca da objectividade na ciência (cf. Campbell (1974) 451).

402 Simmel (1999) 177/180. 
reconhecem nas suas realizações, cada indivíduo se reconhece na história graças à rota marcada pelo "uso da intuição", não obstante só o possamos conceber como "história" se imaginarmos, como sugere Simmel, um sujeito ideal que pareça desenvolver-se através do trânsito de uma intuição para outra, o qual se exercita num âmbito muito originário, onde nos reconhecemos apenas como "exemplos" de concreções ou cristalizações supra-individuais. Advertirmo-nos como vivos é - poderia dizer-se assim - a primeira intuição "transcendental", é a porta de entrada para todas as outras intuições, nas quais o "eu", o "tu", o "ver", "ouvir", "pensar", "compreender", etc., são protofenómenos que interagem no cenário de uma vida supra-individual, em cujo pulsar cada indivíduo pode perceber-se a si mesmo somente como um caso particular (ou exemplo) da vivacidade propriamente dita:

“Mostra-se, por isso, que o ritmo, a constante mobilidade da vida, é o portador formal da compreensão. Inclusivamente naqueles contextos de conteúdos fácticos [Sachgehalte] que, por sua vez, tornam originalmente compreensível o acontecer vivente concreto destes conteúdos fácticos. Mas a autêntica e efectiva vivacidade daquele sujeito ideal é uma conformação e objectivação duma vivacidade tal que advertimos em nós próprios, mas como uma conformação e objectivação supra-individual de que somos, por assim dizer, apenas um exemplo." 403

Recorrendo a uma metáfora musical, segundo o fio do fluxo de mobilidade que Simmel descreve como "portador formal da compreensão" poderíamos sugerir que a vida individual como ser compreensivo parece consistir fundamentalmente em "seguir o ritmo".

403 Simmel (1999) 175/178. 


\section{Bibliografía}

AGÍs VILLAVERDE, Marcelino (2000): “El sentido del ser interpretado". In: Valdés, M. et al: Con Paul Ricoeur: indagaciones hermenéutica. Caracas: Monte Ávila Editores, pp. 91-114.

BERGSON, H. (1985): La evolución creadora. Trad. M. L. Pérez, Barcelona: Planeta-Agostini.

CAMPBELL, D. T. (1988): “A General 'Selection Theory' as Implemented in Biological Evolution and in Social Belief-Transmission-with-Modification in Sciences". In: Biology and Philosophy 3, 171-177.

CAMPBell, D. T. (1974): “Evolutionary Epistemology". In: P. A. Schilpp (Ed.): The Philosophy of Karl Popper. Vol. 1, La Salle: Open Court, pp. 413-463.

COLEMAN, M. (2002): “Taking Simmel Seriously in Evolutionary Epistemology". In: Studies in History and Philosophy of Science, vol. 33 (Issuel 1), pp. 55-74.

FRANCO, R. (2008): “Intuición y concepto. Ampliación simmeliana de la epistemología de Nietzsche". In: Euphyía. Revista de Filosofía, n² 2, pp. 9-25.

FRANCO, R. (2007): “Ontologie des Lebens als unmittelbare Wahrheit des Denkens. Anmerkungen zu Hegels Leben-Erkennen-Dialektik und Simmels Selbsttranszendenz des Lebens". In: A. Arndt (Ed.), Hegel-Jahrbuch 2007: Das Leben denken. Vol. II, Berlin: Akademie Verlag, pp. 206-213.

HEIDEGGER, M. (1967): Sein und Zeit. Tübingen: Niemeyer.

KANT, I. (1995): Kritik der reinen Vernunft. W. Weischedel (Ed.), Franktfurt a. M.: Suhrkamp. [Edición española: Kant, I. (1997): Crítica de la razón pura, (trad. de P. Ribas), Madrid: Alfaguara.]

POPPER, K. R. (1974): “Campbell on the Evolutionary Theory of Knowledge". In: P. A. Schilpp (Ed.): The Philosophy of Karl Popper, vol. 2, La Salle: Open Court, pp. 1059-1065.

SIMMEL, G. (2001): "Vom Wesen des historischen Verstehens". In: Simmel, G. (1987), Vol. 16, pp. 151-180. [versión castellana: Simmel, G. "De la esencia del comprender histórico". In: El individuo y la libertad. Ensayos sobre crítica de la cultura. S. Mas (tr.). Barcelona: Península.]

SIMMEL, G. (1992): Über eine Beziehung der Selektionslehre zur Erkenntnistheorie. In: Simmel, G. (1987-), Vol. 5, pp. 62-74.

SIMMEL, G. (1987-): Gesamtausgabe in 24 Bände. O. Rammstedt (Ed.): Frankfurt am Main, Suhrkamp.

SIMMEL, G. (1989): Aufsätze 1887 bis 1890; Über sociale Differenzierung; Die Probleme der Geschichtsphilosophie (1892). In: Simmel, G. (1987-), Vol. 2.

SIMMEL, G. (1992): Aufsätze und Abhandlungen 1894-1900. In: Simmel (1987-). Eds. H.-J. Dahme - D. Frisby (Eds.), Vol. 5.

SIMMEL, G. (1999): Der Krieg und die geistigen Entscheidungen [u.a]. In: Simmel (1987-). Eds. G. Fritzi; O. Rammstedt . Vol. 16.

WALDENFELS, W. (2004), "El poder de los acontecimientos". Azafea. Revista de filosofía, 6. Trad. R. Franco, pp. 139-151. 
